\title{
Theory Content, Question-Behavior Effects, or Form of Delivery Effects for Intention to Become an Organ Donor? Two Randomized Trials
}

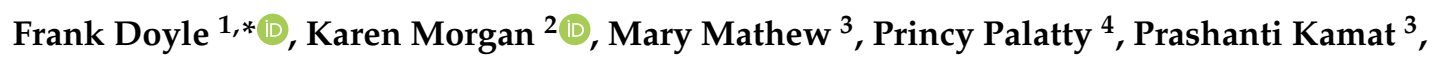 \\ Sally Doherty ${ }^{5}$, Jody Quigley ${ }^{6}$, Josh Henderson ${ }^{6}$ and Ronan $\mathrm{O}^{\prime}$ Carroll ${ }^{6}{ }^{\circ}$ \\ 1 Department of Health Psychology, Royal College of Surgeons in Ireland, D02 DH60 Dublin, Ireland \\ 2 Perdana University-Royal College of Surgeons in Ireland School of Medicine, Selangor, \\ Serdang 43400, Malaysia; karenmorgan@perdanauniversity.edu.my \\ 3 Department of Pathology, Kasturba Medical College, Manipal Academy of Higher Education, Karnataka, \\ Manipal 576104, India; mary.mathew@manipal.edu (M.M.); kamat.prashanti@gmail.com (P.K.) \\ 4 Department of Pharmacology, Father Muller Medical College, Mangalore 575002, Karnataka, India; \\ drprincylouispalatty@gmail.com \\ 5 RCSI Bahrain, Kingdom of Bahrain, Adliya, P.O. Box 15503, Bahrain; sdoherty@rcsi-mub.com \\ 6 Department of Psychology, University of Stirling, Stirling FK9 4LA, UK; \\ jody.quigley@postgrad.manchester.ac.uk (J.Q.); jhendy10@hotmail.co.uk (J.H.); \\ ronan.ocarroll@stir.ac.uk (R.O.) \\ * Correspondence: fdoyle4@rcsi.ie
}

Received: 11 March 2019; Accepted: 9 April 2019; Published: 11 April 2019

\begin{abstract}
Eliciting different attitudes with survey questionnaires may impact on intention to donate organs. Previous research used varying numbers of questionnaire items, or different modes of intervention delivery, when comparing groups. We aimed to determine whether intention to donate organs differed among groups exposed to different theoretical content, but similar questionnaire length, in different countries. We tested the effect of excluding affective attitudinal items on intention to donate, using constant item numbers in two modes of intervention delivery. Study 1 : A multi-country, interviewer-led, cross-sectional randomized trial recruited 1007 participants, who completed questionnaires as per group assignment: including all affective attitude items, affective attitude items replaced, negatively-worded affective attitude items replaced. Study 2 recruited a UK-representative, cross-sectional sample of 616 participants using an online methodology, randomly assigned to the same conditions. Multilevel models assessed effects of group membership on outcomes: intention to donate (primary), taking a donor card, following a web-link (secondary). In study 1 , intention to donate did not differ among groups. Study 2 found a small, significantly higher intention to donate in the negatively-worded affective attitudes replaced group. Combining data yielded no group differences. No differences were seen for secondary outcomes. Ancillary analyses suggest significant interviewer effects. Contrary to previous research, theoretical content may be less relevant than number or valence of questionnaire items, or form of intervention delivery, for increasing intention to donate organs.
\end{abstract}

Keywords: organ donation; affective attitudes; question-behavior effect; randomized trial; psychological theory; public health

\section{Introduction}

Organ donation is a successful intervention, with most 5-year survival rates in excess of $70 \%$. However, there is a chronic shortage of organs available for transplantation, suggesting a need to 
vastly increase the number of either live or posthumous donations. For example, despite the fact that 95\% of Americans support organ donation, only 54\% have signed up as donors, with currently over 116,000 people on the national transplant waiting list (https://www.organdonor.gov/statistics-stories/ statistics.html; [1]). Internationally, the gap between public support and registration can be larger (e.g., http://www.organdonation.nhs.uk; [1]). Therefore, studies investigating how to increase donation rates are of vital international importance.

One particular focus of organ donation research concerns the theoretical content of communication to enhance donation intentions. Recent US and UK findings have shown that cognitive evaluations of the evidence around organ donation are actually less important than emotional or visceral beliefs or reactions, known as 'affective attitudes' [1-3]. For example, studies have shown that affective attitudes were typically associated with registration behavior, whereas cognitive attitudes were not $[1,2]$. Examples of negative affective attitudes are the 'ick factor' - a basic or visceral reaction of disgust to the thought of organ donation; or even the 'jinx factor' - a fear factor or superstitious belief that simply registering for organ donation will increase the probability that something bad or fatal will happen to an individual. A positive affective attitude would be 'perceived benefits', such as bringing meaning to the death of a loved one. These 'ick' or 'jinx' factors have been associated with lower intention to donate, whereas cognitive attitudes or subjective norms were not [1-3].

$\mathrm{O}^{\prime}$ Carroll and colleagues have argued that the use of anticipated regret interventions could perhaps overcome these affective attitudes, yielding higher intention to donate and even higher donor registration [3-5]. One possible mechanism of action is that anticipated regret may help overcome a "gut feelings"/affective attitudes (system 1 decision making) response, e.g., disgust/"no thanks". Asking people to think about whether they would regret it later if they did not become a posthumous organ donor encourages reflection and deliberation (system 2 decision making) and could raise intention to become an organ donor [6].

The hypothesis was that as people are motivated to avoid regret, promotion of anticipated regret should motivate people to undertake action to avoid future emotional consequences-i.e., having higher anticipated regret over not donating organs would actually increase rates of donation. For example, self-reported intention to donate was increased by using two items on anticipated regret in a study of 193 non-donor participants [3]. However, these findings failed to replicate in a study of 9,139 nonregistered donors, using verified organ donor registration as the primary outcome [5]. The INORDAR trial randomly assigned participants to one of four groups: a no questionnaire control group, who simply received a letter inviting them to consider organ donor registration; a questionnaire control group, who received a letter and questionnaire with items assessing intention and affective attitudes; a Theory of Planned Behavior (TPB) group, who also received items assessing TPB constructs along with the same items as the questionnaire controls; and an anticipated regret group, who received all items as above, but also two extra items assessing anticipated regret. Six months after receipt of the invitation/questionnaires, the highest rate of registration was actually seen in the no questionnaire control group (6.39\% versus $4.51-5.40 \%$ in other groups). Thus, this well designed, theory-based intervention actually did harm by reducing donor registration [5].

Why did this intervention fail? The authors speculated that this may have been the result of negative priming effects i.e., people were cued to think more negatively about organ donation by completion of negative affective attitude items and this may have counteracted any positive effects of the anticipated regret intervention. This was tested by Doherty et al. [1] in 349 non-donors, using the same questionnaire items as per the INORDAR trial. Doherty et al. [1] tested 3 groups, using an interviewer methodology, with intention to donate as the primary outcome: the first group replicated the anticipated regret group from INORDAR, the second group used the same items, but omitted affective attitudes, while the third group omitted negatively-worded affective attitudinal items only. The second group reported significantly higher intention to donate than the replication group, and were marginally more likely to take an organ donor card from interviewers after the study (an effect 
entirely mediated by intention), supporting the hypothesis that the assessment of affective attitudes may have counteracted any positive benefits of an anticipated regret intervention.

However, there may be other explanations for these findings. The mere measurement effect, or question-behavior effect, is defined as the influence of any sort of questioning on subsequent performance of any given behavior, and recent meta-analyses have shown a small effect on behavior [7-9]. While the INORDAR study used filler/dummy items to ensure the same length of questionnaire across the three intervention groups, the number of questionnaire items in the Doherty et al. [1] study differed per group as dummy items were not utilized. It is therefore possible that simply including more items decreased intention to donate and indeed actual donor registry behavior, not as a result of the actual theoretical content of the questionnaires. Furthermore, the form of delivery differed between the studies. INORDAR used postal methods, whereas Doherty et al. [1] used student interviewers to ascertain people's intentions to donate. It is therefore possible that a social desirability element played a role in these findings [10-12]. Furthermore, the form of delivery may interact with the theoretical content [13]. For example, face-to-face interventions appear to be more effective than online versions of the same intervention [14], while 'therapist effects' are well established-where variability in therapists accounts for some of the effects of a given intervention [15,16]. A further potentially important issue is whether different countries and cultures respond differently to these theoretical constructs $[17,18]$, which was not measured in previous studies. We therefore extend previous research here by addressing these issues in two related randomized trials. Specifically, we aimed to determine whether intention to donate organs differed among groups exposed to different theoretical content, but similar questionnaire length, in different countries. We also investigated whether findings were replicated using different forms of delivery. Objectives were as follows:

- $\quad$ To replicate the findings of Doherty et al. [1], by determining whether intention to donate was different among groups exposed to differential levels of affective attitudes, when using a similar number of questionnaire items in each exposure

- $\quad$ Determine whether findings were similar in different countries and cultures

- $\quad$ Ascertain whether results are similar with face-to-face or web-based methodologies

\section{Materials and Methods}

\subsection{Context}

Ireland, Malaysia and India do not have an organ donor registry, while the UK does. Potential donors in the first three countries can indicate their willingness to donate in nationally-accepted formats, i.e., carrying a signed donor card (or using the approved app; Ireland only), endorsing own driver's license as a potential future donor, discussing one's future wishes with family. As next-of-kin can veto organ donation, even with a prior indication of willingness to donate from the potential donor, we primarily used this variable to classify people as non-donors. That is, donors were defined as those who had not discussed their intentions to become donors with family and fulfilled one of the following criteria: carried the donor card, used the donor app or indicated their wishes on their driver's license [1]. Those who had already donated an organ were classified as donors $(n=13)$. For data collected in the UK, participants who had not yet signed up to the national registry were defined as non-donors.

Two randomized trial were conducted, using largely the same item content and procedures as per Doherty et al. [1] and the original INORDAR questionnaire items (UK data). Study 1 was pre-registered: NCT02825862. Study 2 was not. We follow the CONSORT and TIDiER statements for appropriate RCT and intervention reporting $[19,20]$ (Appendices A and B).

\subsection{Trial Design}

In both studies a cross-sectional, three-arm, parallel randomized trial with 1:1:1 allocation ratio design was used. Study 1 was originally to recruit in Bahrain, but this site withdrew and Manipal, India was instead added. No changes to intervention or eligibility criteria were made. 


\subsection{Participants}

Participant eligibility criteria were as follows: adults, 18 years and older. Refusal to participate was the only exclusion criteria, except for Malaysia, where non-English speakers were also excluded. Only non-donors (see above) were included in the randomized trial and were asked to provide outcome measures etc. The protocol was approved by the Research Ethics Committees (RECs) in each site (RCSI Dublin REC1048bb; UK-Stirling University General University Ethics Panel [No. 188]; Malaysia, RCSI PU REC-PUIRBH0097; India-Kasturba Hospital Institutional Ethics Committee IEC 134/2017). An opportunistic sample in each country was recruited (study 1). A nationally-representative sample of UK non-donors was recruited in study 2 using an online methodology (Qualtrics subject panel). After provision of a study information leaflet and consenting to participate, participants provided demographic information and then answered 27 questions about organ donation beliefs.

\subsection{Interventions and Procedures}

For both study 1 and 2, allocated groups were as follows:

- Group 1: No-intervention replication group, who completed the entire questionnaire (similar to the anticipated regret group from INORDAR), replicating methods of $\mathrm{O}^{\prime}$ Carroll et al. [3].

- Group 2: Omitted affective attitudes group. All 16 questions on affective attitudes were deleted, with dummy questions (e.g., about politics) substituted for these deleted questions (as in the INORDAR trial).

- Group 3: Omitted 12 negatively-worded affective attitudes only, which were substituted with the same questions as Group 2.

We tested a question-behavior effect with or without affective attitudes, assessing whether completion of affective attitude items reduces intention to donate, but including dummy items to overcome the mere measurement (question-behavior) effect. Two modalities of intervention delivery were tested to determine if a social desirability effect, i.e., being in the presence of an interviewer, masks the effects of including affective attitudes on intention to donate [21].

\subsection{Materials/Measures}

Three separate questionnaires, one for each group allocation, were used. Materials are available from the authors. All items used 7-point ratings (1 indicating lowest agreement, 7 maximum agreement). We adopted the measures from INORDAR (replicating the procedures used in Doherty et al. [1]), with minor wording changes to reflect the fact that there is no organ donor registry in Ireland, India or Malaysia. In the UK site the original wording was used (both studies). For example, for the primary outcome, intention to donate, non-donor participants were asked the following:

- $\quad$ UK: "I will definitely register for organ donation in the next few months"

- $\quad$ Non-UK: "I will definitely sign up for organ donation and discuss this with my family in the next few months"

Questionnaires assessed the following theoretical content:

Affective attitudes were assessed using 16 items, tapping areas such as the ick factor (three items, alpha $=0.83$, e.g., "The idea of organ donation is somewhat disgusting"), the jinx factor (three items, alpha $=0.72$, e.g., "People who donate their organs risk displeasing God or nature"), medical distrust (four items, alpha $=0.83$, e.g., "If I sign an organ donor card, doctors might not try so hard to save my life"), perceived benefits (four items, alpha $=0.61$, e.g., "Organ donation allows something positive to come out of a person's death"), and bodily integrity (two items, alpha $=0.78$, e.g., "Organ donors may not be resurrected because they don't have all their 'parts'").

Anticipated regret was assessed using two items (alpha $=0.79$, e.g., "If I did not sign up for organ donation (with card, app or license) and discuss this with my family [or, in the UK: 'register for organ donation'] in the next few months I would feel regret"). 
Theory of planned behavior constructs, cognitive attitudes (alpha $=0.86$, two items, e.g., "I support the idea of organ donation for transplantation purposes"), perceived behavioral control (three items, alpha $=0.68$, e.g., "how much control do you have over signing up for organ donation in the next few months?"), and subjective norms (two items, alpha $=0.65$, e.g., "Most people who are important to me think I should sign up for organ donation and confirm this with my family in the next few months") were also assessed. Dummy items included statements such as "Organ donation is a private matter" or "Lack of organ donation is a serious issue".

\subsection{Procedures}

In study 1, undergraduate medical students recruited participants in Ireland (in 4 shopping centers in Dublin, dates ranging from 20th January to 19th February 2016 and 12th January to 1st February 2017) and Malaysia (in and around a number of university campuses, dates ranging from July to December 2016). In the UK, a postgraduate student (MSc in Psychology) recruited participants in 11 public libraries in Stirling (12th May to 28th August 2017). In India, the researchers (MM and PP) recruited participants from the University campus of Manipal, Rotary Club Manipal and students from St. Aloysius College, Mangalore from 19th September 2017 to 13th October 2017. No specific standardized training was given, but investigators were available to clarify any issues on request. Study 2 did not utilize interviewers (and was therefore double-blind, whereas study 1 was single-blind). Questionnaires were distributed in different ways. In study 1, the Irish site interviewers used iPads, with paper-and-pencil being used in the other sites. Interviewers approached potential participants, who were interviewed if they consented to this single anonymous interview. Interviewers then completed questionnaires on behalf of participants. After the interview, where applicable (not in the UK), it was also recorded whether interviewers offered an organ donor card and whether participants accepted the card (leaflet in the UK). Apart from the UK, all study 1 interviews were face-to-face, typically lasting 10-20 minutes. In the UK, participants were given questionnaires to complete in the library which they then returned to the researcher. In study 2, the mode of delivery was web-based, recruiting a population-representative sample of UK adults. Participants (aged 18+) from England and Scotland who had never previously donated an organ and were not registered as organ donors were asked to take part in a digital survey (using the U.K. Qualtrics participant panel) in September-October 2017. All participant data were captured digitally through online questionnaires administered by a Qualtrics digital platform. Participants viewed study information and were asked to provide their informed consent to the digital survey. On completion of the survey, participants were thanked and given a debrief statement about the study. Participants were free to leave the survey at any time and also leave questions blank if they wished, or could start and finish the items at any time. Fidelity tests were not conducted.

\subsection{Outcomes}

Intention to donate, assessed by two items on a 7-point scale (e.g., "I will definitely sign up for organ donation and discuss this with my family in the next few months"), was the primary outcome. The secondary outcome (where applicable), was taking a donor card after the interview (study 1; yes/no), or asking participants if they would like to be taken to the organ donor registry website (study 2; yes/no).

\subsection{Sample Size}

As recruitment was expected to vary considerably across sites, a formal power calculation was not conducted, but instead we aimed to recruit as many participants as possible within the allocated timeframes. We estimated a possible 750 participants for study 1 based on Doherty et al. [1], and a lower number for study 2 . This would also allow for within-site differences to be explored. 


\subsection{Randomization}

Study 1: Participants were block-randomized (random block sizes ranging from 3-15) using the ralloc command for Stata 13.0 (StataCorp LLC, College Station, TX, USA). FD supplied eight separate (four for Dublin, two for Malaysia, two for India) participant recruitment Excel sheets to the Dublin interviewers and the lead investigators in Malaysia and India, which showed the order in which participants should be recruited. In the UK (study 1), participants were randomly allocated using a random number generator (researchrandomiser.org). Participants were then recruited sequentially, as per the random recruitment order. Therefore, the participants were blinded to group allocation, but interviewers were not. In Study 2 the Qualtrics software automatically randomized the on-line participants to one of the 3 conditions using simple randomization, and this was therefore double-blinded.

\subsection{Statistical Methods}

As per CONSORT guidelines, we did not ascertain between group differences at baseline [19,22]. As this is a cross-sectional study, with outcomes recorded at the same time as exposures, imputation procedures were not considered, and all participants were analyzed as per original group allocation. Using group 1 (INORDAR replication group) as the reference, we used multilevel linear and logistic modelling to ascertain differences in intention score and taking of organ donor cards among groups within each site, with countries as the random intercept, using the mixed and melogit commands in Stata 15.0 (StataCorp LLC, College Station, TX, USA). We ran three main models, for study 1, study 2 and then combined. We also ran sensitivity analyses, omitting the UK face-to-face data, as this involved relatively little interaction with the researcher. In post-hoc analysis, we explored the Irish data only, as this dataset contained variables indicative of more levels within the data (4 different interviewers).

\section{Results}

\subsection{Participant Profile}

The participant flow chart is shown in Figure 1.

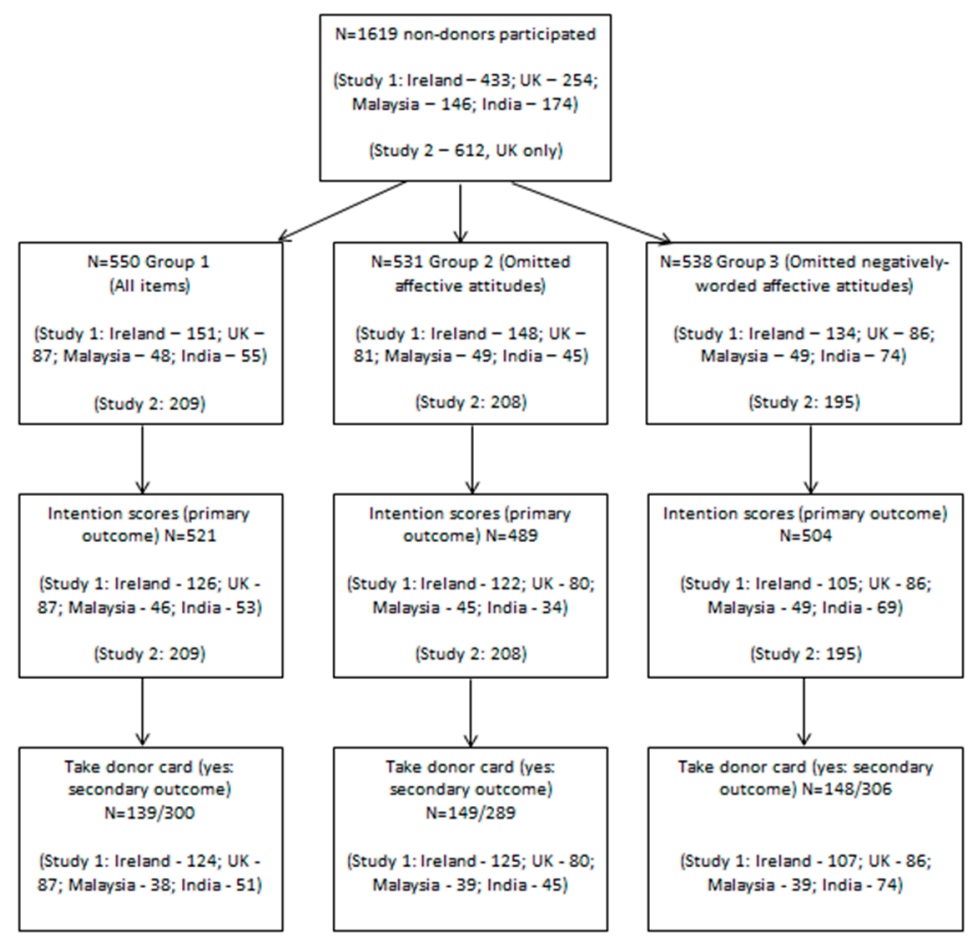

Figure 1. Participant flowchart and outcome ascertainment. 
Table 1. Sample description.

\begin{tabular}{|c|c|c|c|c|c|c|c|c|c|c|c|c|c|}
\hline & \multicolumn{5}{|c|}{ Study 1} & \multicolumn{4}{|c|}{ Study 2} & \multicolumn{4}{|c|}{ Combined Data } \\
\hline & $\begin{array}{l}\text { Study } 1 \\
\text { N }\end{array}$ & $\begin{array}{l}\text { Study 1, } \\
\text { All } \\
\text { Groups }\end{array}$ & Group 1 & Group 2 & Group 3 & $\begin{array}{c}\text { Study } 2 \\
\text { Overall } \\
(\mathrm{N}=612 \\
\text { for All) }\end{array}$ & Group 1 & Group 2 & Group 3 & $\begin{array}{l}\text { Combined } \\
\text { Samples }\end{array}$ & Group 1 & Group 2 & Group 3 \\
\hline Age (mean, SD) & 1005 & $34.4(18.1)$ & $34.6(17.9)$ & $34.8(18.1)$ & $33.7(18.2)$ & $50.4(15.6)$ & $50.8(15.3)$ & $49.5(16.1)$ & $51.0(15.4)$ & $40.4(18.9)$ & 40.7 (18.7) & $40.6(18.8)$ & $40.0(19.1)$ \\
\hline Women & 1004 & $54.0 \%$ & $50.7 \%$ & $56.1 \%$ & $55.3 \%$ & $50.3 \%$ & $51.2 \%$ & $52.4 \%$ & $47.2 \%$ & $52.6 \%$ & $50.9 \%$ & $54.6 \%$ & $52.3 \%$ \\
\hline $\begin{array}{c}\text { Private health } \\
\text { insurance }{ }^{+}\end{array}$ & 691 & $50.7 \%$ & $51.2 \%$ & $47.2 \%$ & $53.7 \%$ & $t$ & + & + & + & - & - & - & - \\
\hline $\begin{array}{c}\text { Interview location } \\
\text { (anonymized, } \\
\text { Ireland only) } \\
1 \\
2 \\
3 \\
4 \\
5\end{array}$ & 433 & $\begin{array}{l}26.3 \% \\
34.2 \% \\
27.5 \% \\
8.08 \% \\
3.93 \%\end{array}$ & $\begin{array}{l}30.5 \% \\
33.8 \% \\
23.2 \% \\
7.95 \% \\
4.64 \%\end{array}$ & $\begin{array}{l}22.3 \% \\
35.2 \% \\
32.4 \% \\
6.76 \% \\
3.38 \%\end{array}$ & $\begin{array}{l}26.1 \% \\
33.6 \% \\
26.9 \% \\
9.70 \% \\
3.73 \%\end{array}$ & $\mathrm{n} / \mathrm{a}$ & $\mathrm{n} / \mathrm{a}$ & $\mathrm{n} / \mathrm{a}$ & $\mathrm{n} / \mathrm{a}$ & - & - & - & - \\
\hline \multicolumn{14}{|l|}{$\begin{array}{c}\text { Do you know someone } \\
\text { who (\% yes) }\end{array}$} \\
\hline has received an organ & 992 & $18.2 \%$ & $17.0 \%$ & $19.0 \%$ & $18.5 \%$ & $11.1 \%$ & $12.0 \%$ & $10.6 \%$ & $10.8 \%$ & $15.5 \%$ & $15.1 \%$ & $15.7 \%$ & $15.7 \%$ \\
\hline needs an organ & 997 & $11.9 \%$ & $10.0 \%$ & $13.6 \%$ & $12.3 \%$ & $3.59 \%$ & $4.78 \%$ & $4.33 \%$ & $1.54 \%$ & $8.76 \%$ & $8.01 \%$ & $9.92 \%$ & $8.40 \%$ \\
\hline has donated an organ & 994 & $13.1 \%$ & $11.9 \%$ & $15.1 \%$ & $12.3 \%$ & $6.86 \%$ & $8.61 \%$ & $5.29 \%$ & $6.67 \%$ & $10.7 \%$ & $10.6 \%$ & $11.2 \%$ & $10.3 \%$ \\
\hline Ever donated blood & 998 & $34.6 \%$ & $33.1 \%$ & $37.3 \%$ & $33.4 \%$ & $31.2 \%$ & $37.3 \%$ & $28.9 \%$ & $27.2 \%$ & $33.3 \%$ & $34.7 \%$ & $34.0 \%$ & $31.2 \%$ \\
\hline
\end{tabular}

† National health insurance for all citizens in UK; n/a -not applicable. 
Data on non-responders were not collected. In study 1, a total of 1007 non-donors participated, of whom 341, 323 and 343 were allocated to groups 1-3 respectively, with outcomes ascertained for 312, 281, 309 (intentions) and 300, 289 and 306 (taking donor card) respectively. In study 2, 612 non-donors were assigned to groups 1-3 in the following numbers: 209, 208 and 195, with intention scores and the secondary outcome of linking to the organ donor website available for all.

Baseline data is available in Table 1, stratified by groupMean age for study 1 was lower than for study 2 and approximately half of the sample in each study were women. Overall, approximately one third had donated blood. In the combined data, $15.5 \%$ knew someone who had received an organ, $8.76 \%$ knew someone who needed an organ and $10.7 \%$ knew someone who had donated an organ, although prevalence varied among studies and conditions. Variables differed considerably across countries (Appendix C).

\subsection{Outcomes}

Outcomes are summarized in Table 2. Mean intention scores were overall lower for study 2 than for study 1 , and proportions of people who transferred to the organ donor website were much lower than the proportions who accepted a donor card.

Table 3 shows the results of the multi-level models predicting intention and behavior by group allocation. There were no significant differences seen for primary or secondary outcomes among groups for either study 1 or the combined data. In study 2, group 3 demonstrated a small but statistically higher intention score in comparison to group 1, but this did not translate into behavior, with no differences among groups for subsequent linkage to the UK organ donor website. A sensitivity analysis, omitting the UK face-to-face data, did not change the results (data not shown).

\subsection{Ancillary Analyses}

In exploratory analyses, we also estimated the effects of different researchers on outcomes in the Irish data only, as this was the only dataset to record the interviewers. There was significant impact on intention scores, irrespective of group, depending on the researcher involved, with no impact by group exposure (Table 3).

\section{Discussion}

In two randomized studies, the overall results suggest no effects of affective attitudinal content on intention to donate or subsequent donor behaviors when the number of questionnaire items is held constant. In study 1, a single-blind, multi-country, face-to-face delivered intervention, no differences in primary or secondary outcomes were seen according to affective attitudinal content. In study 2, which was double-blind and web-based, a small, but significantly higher intention score was seen for the group which omitted negatively-worded affective attitudinal items, but this did not translate into increased organ donor behavior via linkage to the organ donor registration website.

The results are in direct contrast to previous research and fail to replicate the findings of Doherty et al. [1], suggesting that when the numbers of questionnaire items are held constant, there was no effect of theory-content on intention to donate or donor behavior. It could be that the question-behavior effect in this instance is powerful enough to overcome the negative contextual cueing priming effect of including affective attitudes [5]. The results also suggest a potential reason for the failure of the INORDAR trial [5]. One reason for the lower donation rates in this trial may simply be due to having a higher number of questionnaire items in the intervention groups, when compared to a no-questionnaire control group. This could also suggest that theoretical content was simply less important than number of questionnaire items participants had to complete. 
Table 2. Summary of outcomes (intention and taking card/website transfer).

\begin{tabular}{|c|c|c|c|c|c|c|c|c|c|c|c|c|c|}
\hline & \multicolumn{5}{|c|}{ Study 1} & \multicolumn{4}{|c|}{ Study 2} & \multicolumn{4}{|c|}{ Combined Data } \\
\hline & $\begin{array}{l}\text { Study } 1, \\
\quad \text { N }\end{array}$ & $\begin{array}{l}\text { Study 1, } \\
\text { All } \\
\text { Groups }\end{array}$ & Group 1 & Group 2 & Group 3 & $\begin{array}{l}\text { Study } 2 \text { Overall } \\
(\mathrm{N}=612 \text { for All) }\end{array}$ & Group 1 & Group 2 & Group 3 & $\begin{array}{l}\text { Combined } \\
\text { Samples }\end{array}$ & Group 1 & Group 2 & Group 3 \\
\hline Intention (mean, SD) & 902 & $4.41(1.60)$ & $4.44(1.66)$ & $4.30(1.57)$ & $4.47(1.56)$ & 3.25 (1.54) & $3.13(1.49)$ & $3.19(1.56)$ & $3.44(1.56)$ & $3.94(1.68)$ & $3.91(1.72)$ & $3.83(1.66)$ & $4.07(1.64)$ \\
\hline Taking donor card (yes, \%) & 895 & $48.7 \%$ & $46.3 \%$ & $51.6 \%$ & $48.4 \%$ & - & - & - & - & - & - & - & - \\
\hline $\begin{array}{l}\text { Transferred to organ } \\
\text { donor website }\end{array}$ & - & - & - & - & - & $7.03 \%$ & $6.22 \%$ & $6.25 \%$ & $8.72 \%$ & - & - & - & - \\
\hline $\begin{array}{l}\text { Combined behavioral } \\
\text { outcome (Taking card or } \\
\text { website transfer) }\end{array}$ & - & - & - & - & - & - & - & - & - & $31.8 \%$ & $29.9 \%$ & $32.6 \%$ & $32.9 \%$ \\
\hline
\end{tabular}

Table 3. Results of regression models predicting outcomes.

\begin{tabular}{|c|c|c|c|c|c|c|c|c|}
\hline & \multirow[b]{2}{*}{ Intention } & \multicolumn{4}{|c|}{ Primary Outcome (Intention) } & \multicolumn{3}{|c|}{ Secondary Outcomes (Card/Website) } \\
\hline & & $\beta$ & Std. Err. & $95 \% \mathrm{CI}$ & $p$ & OR & $95 \% \mathrm{CI}$ & $p$ \\
\hline \multirow{3}{*}{ Study 1} & Group 1 & Ref. & - & - & - & Ref. & - & - \\
\hline & Group 2 & -0.120 & 0.130 & -0.375 to 0.134 & 0.354 & 1.28 & 0.890 to 1.84 & 0.183 \\
\hline & Group 3 & 0.025 & 0.127 & -0.224 to 0.274 & 0.850 & 1.34 & 0.932 to 1.93 & 0.113 \\
\hline \multirow{3}{*}{ Study 2} & Group 1 & Ref. & - & - & - & Ref. & - & - \\
\hline & Group 2 & 0.061 & 0.150 & -0.234 to 0.355 & 0.686 & 1.00 & 0.426 to 2.03 & 0.990 \\
\hline & Group 3 & 0.307 & 0.153 & 0.007 to 0.606 & $0.044^{*}$ & 1.44 & 0.680 to 3.05 & 0.341 \\
\hline \multirow{3}{*}{ Combined data } & Group 1 & Ref. & - & - & - & & - & - \\
\hline & Group 2 & -0.047 & 0.098 & -0.239 to 0.146 & 0.637 & 1.22 & 0.882 to 1.70 & 0.227 \\
\hline & Group 3 & 0.136 & 0.098 & -0.055 to 0.328 & 0.163 & 1.37 & 0.982 to 1.90 & 0.063 \\
\hline \multirow{7}{*}{ Exploratory analyses-Irish data only } & Group 1 & Ref. & - & - & - & Ref. & - & - \\
\hline & Group 2 & -0.124 & 0.199 & -0.514 to 0.266 & 0.533 & 1.55 & 0.916 to 2.63 & 0.102 \\
\hline & Group 3 & -0.184 & 0.207 & -0.590 to 0.221 & 0.373 & 1.52 & 0.877 to 2.63 & 0.136 \\
\hline & Researcher 1 & Ref. & - & - & - & Ref. & - & - \\
\hline & Researcher 2 & -0.809 & 0.250 & -1.30 to -0.319 & $0.001^{* *}$ & 0.42 & 0.210 to 0.851 & $0.016^{*}$ \\
\hline & Researcher 3 & -0.395 & 0.227 & -0.840 to 0.049 & 0.081 & 0.34 & 0.184 to 0.647 & $0.001 * *$ \\
\hline & Researcher 4 & 0.283 & 0.235 & -0.177 to 0.745 & 0.227 & 0.63 & 0.326 to 1.22 & 0.174 \\
\hline
\end{tabular}

${ }^{*} p<0.05,{ }^{* *} p<0.01$; Group 1-replicating INORDAR; Group 2—omitting all affective attitudinal items; Group 3-omitting negatively-worded affective attitudinal items. 
The differences in results between study 1 and 2 deserve comment. First, intention scores and behaviors were significantly lower in the web-based study 2 than in the interviewer-based study 1 , supporting the notion that having interviewers can lead to social desirability bias in respondents' answers and behaviors [8,10-12]. Social desirability has been shown to be related to higher intention to donate scores, albeit not higher proxy donation behaviors, in a recent study on reciprocal altruism in which the face-to-face interviews were conducted by a single researcher [21]. This is similar to the findings of study 2-where the negatively-worded affective attitudes omitted group showed highest intention to donate. Therefore, the social desirability elements of study 1 may have masked these effects. The major caveat is, however, that there was no effect on behavior, even with higher intention scores, as has been observed in previous research [21]. Second, an alternative possible explanation for differences in findings from study 1 to study 2 is the modification of questionnaire items needed for countries without an organ donor register. However, this is unlikely to be the case, as the UK data from study 1 also had non-significant results. Therefore, the differences in intention scores and behaviors between studies 1 and 2 are more likely to be due to the different forms of delivery [13]. Third, although the study was conducted across countries with very different cultural contexts, the results were similar in that no effects for group membership were seen in individual countries (data not shown), suggesting a robust effect of questionnaire length on outcomes. Future research could consider countries with high organ donation rates (e.g., Spain) or legislative frameworks (e.g., opt-in versus opt-out), but also the target populations (living donor versus post-mortem donors), to determine if these influence attitudes and overall results.

As mentioned above, therapist-specific effects are well-established in other areas of research $[15,16]$, including charitable donation [23]. Indeed, recent research in smoking cessation intervention suggests that individual counselors explain up to $9 \%$ of the variance in cessation outcomes, and cessation counselors with higher extraversion scores may be more effective $[24,25]$. The ancillary analyses from the present study support this finding in terms of organ donation, with significantly different primary and secondary outcomes reported in the Irish data, which vary not as a result of group membership, but by interviewer. This replicates and supports the findings of Doherty et al. [1], who also demonstrated significantly different intention and behavior scores by interviewers. While it is in contrast to previous research which has suggested that the form of delivery of organ donation communications is not relevant [26], the current findings, along with those of Doherty et al. [1], suggest that the individual who is delivering the intervention may be a critical determinant of organ donation research in particular, health psychology and behavioral medicine research more generally. Form of delivery as an 'active ingredient' of behaviour change interventions has largely been ignored to date [13].

\section{Limitations and Strengths}

We acknowledge several limitations inherent in the study. Self-reported intention was the primary outcome, albeit we had (proxy) behavioral measures as secondary outcomes. The design is cross-sectional, so we have no indication of subsequent behavior or attitudes to organ donation, or indeed any ability to account for initial elevation bias in the questionnaires [27]. Minor wording changes were required in study 1 for 3 of the participating countries, where discussions with family and becoming a donor were possibly confounded in the items, although this was not needed for study 2. The design of study 1 was single-blind and it is possible that interviewers approached participants with reference to the group that was next on the randomization list—but, again, this was not the case in study 2. However, despite these limitations, results were consistent across both outcomes, suggesting a robust effect. Anticipated regret was included in all groups and it is possible that results may be different if anticipated regret items were not included in one or more groups. A recent meta-analysis has shown that affective forecasting has a small initial effect on anticipated regret, but effects on later intentions or regret were not significant [28]. Future research should address this, by including a trial arm that does not contain anticipated regret. A power calculation was not conducted beforehand, as we simply required students to recruit for the duration of their research placement (study 1), and we knew 
we would obtain sufficient numbers with four sites recruiting. The sampling techniques used in study 1 limit the generalizability of the results, however, in contrast, we did recruit from four countries and study 2 does involve a population-generalizable sample. We also used 2 methodologies-face-to-face and web-based, increasing generalizability. Other strengths included adopting already-used methods and items from previous research. Another limitation is that we did not adopt a no-questionnaire control group, to compare organ donor intentions and behaviours without exposure to questionnaire (theory) content, as in the original INORDAR trial. Future work should address this.

\section{Conclusions}

In two large randomized trials, intention to become an organ donor was not influenced by the theoretical content of the questionnaire when similar numbers of items were used across conditions, and was only influenced by theoretical content when the form of delivery was internet-based. When testing theory, researchers must use similar numbers of items across conditions to guard against the mere measurement effect, and fully report the form of intervention delivery. There may also be important interventionist effects to consider and investigate in future research.

Author Contributions: Conceptualization, F.D. and R.O.; Data curation, F.D.; Formal analysis, F.D.; Funding acquisition, F.D.; Investigation, F.D., K.M., M.M., J.Q., J.H. and R.O.; Methodology, F.D. and R.O.; Project administration, F.D., M.M. and R.O.; Resources, R.O.; Supervision, K.M.; Writing-original draft, F.D.; Writing—review \& editing, F.D., K.M., M.M., P.P., P.K., S.D., J.Q., J.H. and R.O.

Funding: This research was supported by the RCSI Research Summer School and the RCSI Student Selected Component, who had no role in recruitment, data analysis or interpretation.

Acknowledgments: The authors acknowledge the assistance of the following for data collection: Amanda Villiers-Tuthill, Rishalan A/L Kobu, Jayakiran A/L Radhakrishnan, Nurul Farhana Binti Baharudin, Mehala Balasubramaniam, Deirdre Arthur, Abdullah Haidar, Talal AlHassan, Anna Bennett.

Conflicts of Interest: The authors declare no conflict of interest. The funders had no role in the design of the study; in the collection, analyses, or interpretation of data; in the writing of the manuscript, or in the decision to publish the results.

\section{Appendix A}

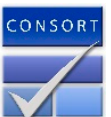

CONSORT 2010 checklist of information to include when reporting a randomised trial *.

\begin{tabular}{|c|c|c|c|}
\hline Section/Topic & Item No & Checklist Item & Reported on Page No \\
\hline \multicolumn{4}{|l|}{ Title and abstract } \\
\hline & $1 \mathrm{a}$ & Identification as a randomised trial in the title & 1 \\
\hline & $1 b$ & $\begin{array}{l}\text { Structured summary of trial design, methods, } \\
\text { results, and conclusions (for specific } \\
\text { guidance see CONSORT for abstracts) }\end{array}$ & $\begin{array}{l}1 \text { (non-structured as per } \\
\text { journal requirements) }\end{array}$ \\
\hline \multicolumn{4}{|l|}{ Introduction } \\
\hline \multirow[t]{2}{*}{ Background and objectives } & $2 a$ & $\begin{array}{l}\text { Scientific background and explanation } \\
\text { of rationale }\end{array}$ & $1-3$ \\
\hline & $2 b$ & Specific objectives or hypotheses & 3 \\
\hline \multicolumn{4}{|l|}{ Methods } \\
\hline \multirow{2}{*}{ Trial design } & $3 a$ & $\begin{array}{l}\text { Description of trial design (such as parallel, } \\
\text { factorial) including allocation ratio }\end{array}$ & 3 \\
\hline & $3 b$ & $\begin{array}{l}\text { Important changes to methods after trial } \\
\text { commencement (such as eligibility criteria), } \\
\text { with reasons }\end{array}$ & 3 \\
\hline
\end{tabular}




\begin{tabular}{|c|c|c|c|}
\hline Section/Topic & Item No & Checklist Item & Reported on Page No \\
\hline \multirow{2}{*}{ Participants } & $4 \mathrm{a}$ & Eligibility criteria for participants & $3-4$ \\
\hline & $4 \mathrm{~b}$ & $\begin{array}{l}\text { Settings and locations where the data were } \\
\text { collected }\end{array}$ & 3,5 \\
\hline Interventions & 5 & $\begin{array}{l}\text { The interventions for each group with } \\
\text { sufficient details to allow replication, } \\
\text { including how and when they were } \\
\text { actually administered }\end{array}$ & $4-5$, TIDIeR checklist \\
\hline \multirow[t]{2}{*}{ Outcomes } & $6 a$ & $\begin{array}{l}\text { Completely defined pre-specified primary } \\
\text { and secondary outcome measures, including } \\
\text { how and when they were assessed }\end{array}$ & 5 \\
\hline & $6 \mathrm{~b}$ & $\begin{array}{l}\text { Any changes to trial outcomes after the trial } \\
\text { commenced, with reasons }\end{array}$ & No changes \\
\hline \multirow{2}{*}{ Sample size } & $7 a$ & How sample size was determined & 5 \\
\hline & $7 \mathrm{~b}$ & $\begin{array}{l}\text { When applicable, explanation of any interim } \\
\text { analyses and stopping guidelines }\end{array}$ & Not applicable \\
\hline \multicolumn{4}{|l|}{ Randomisation: } \\
\hline \multirow[t]{2}{*}{ Sequence generation } & $8 \mathrm{a}$ & $\begin{array}{l}\text { Method used to generate the random } \\
\text { allocation sequence }\end{array}$ & $5-6$ \\
\hline & $8 b$ & $\begin{array}{l}\text { Type of randomisation; details of any } \\
\text { restriction (such as blocking and block size) }\end{array}$ & $5-6$ \\
\hline $\begin{array}{l}\text { Allocation concealment } \\
\text { mechanism }\end{array}$ & 9 & $\begin{array}{l}\text { Mechanism used to implement the random } \\
\text { allocation sequence (such as sequentially } \\
\text { numbered containers), describing any steps } \\
\text { taken to conceal the sequence until } \\
\text { interventions were assigned }\end{array}$ & $5-6$ \\
\hline Implementation & 10 & $\begin{array}{l}\text { Who generated the random allocation } \\
\text { sequence, who enrolled participants, and } \\
\text { who assigned participants to interventions }\end{array}$ & $5-6$ \\
\hline \multirow[t]{2}{*}{ Blinding } & $11 \mathrm{a}$ & $\begin{array}{l}\text { If done, who was blinded after assignment to } \\
\text { interventions (for example, participants, care } \\
\text { providers, those assessing outcomes) } \\
\text { and how }\end{array}$ & $5-6$ \\
\hline & $11 b$ & $\begin{array}{l}\text { If relevant, description of the similarity of } \\
\text { interventions }\end{array}$ & 4 \\
\hline \multirow{2}{*}{ Statistical methods } & $12 \mathrm{a}$ & $\begin{array}{l}\text { Statistical methods used to compare groups } \\
\text { for primary and secondary outcomes }\end{array}$ & 6 \\
\hline & $12 b$ & $\begin{array}{l}\text { Methods for additional analyses, such as } \\
\text { subgroup analyses and adjusted analyses }\end{array}$ & 6 \\
\hline \multicolumn{4}{|l|}{ Results } \\
\hline \multirow[t]{2}{*}{$\begin{array}{l}\text { Participant flow (a diagram } \\
\text { is strongly recommended) }\end{array}$} & $13 a$ & $\begin{array}{l}\text { For each group, the numbers of participants } \\
\text { who were randomly assigned, received } \\
\text { intended treatment, and were analysed for } \\
\text { the primary outcome }\end{array}$ & 7-Figure 1 \\
\hline & $13 b$ & $\begin{array}{l}\text { For each group, losses and exclusions after } \\
\text { randomisation, together with reasons }\end{array}$ & 7-Figure 1 \\
\hline \multirow[t]{2}{*}{ Recruitment } & $14 \mathrm{a}$ & $\begin{array}{l}\text { Dates defining the periods of recruitment } \\
\text { and follow-up }\end{array}$ & 5 \\
\hline & $14 \mathrm{~b}$ & Why the trial ended or was stopped & Not applicable \\
\hline Baseline data & 15 & $\begin{array}{l}\text { A table showing baseline demographic and } \\
\text { clinical characteristics for each group }\end{array}$ & 8-Table 1, 21-Appendix \\
\hline Numbers analysed & 16 & $\begin{array}{l}\text { For each group, number of participants } \\
\text { (denominator) included in each analysis and } \\
\text { whether the analysis was by original } \\
\text { assigned groups }\end{array}$ & 6,7-Figure 1 \\
\hline
\end{tabular}




\begin{tabular}{|c|c|c|c|}
\hline Section/Topic & Item No & Checklist Item & Reported on Page No \\
\hline \multirow[t]{2}{*}{ Outcomes and estimation } & $17 \mathrm{a}$ & $\begin{array}{l}\text { For each primary and secondary outcome, } \\
\text { results for each group, and the estimated } \\
\text { effect size and its precision (such as } 95 \% \\
\text { confidence interval) }\end{array}$ & $\begin{array}{l}11 \\
10 \text {-Table } 2 \\
12-\text { Table } 3\end{array}$ \\
\hline & $17 \mathrm{~b}$ & $\begin{array}{l}\text { For binary outcomes, presentation of both } \\
\text { absolute and relative effect sizes is } \\
\text { recommended }\end{array}$ & $\begin{array}{l}10 \\
10 \text {-Table } 2 \\
12 \text {-Table } 3\end{array}$ \\
\hline Ancillary analyses & 18 & $\begin{array}{l}\text { Results of any other analyses performed, } \\
\text { including subgroup analyses and adjusted } \\
\text { analyses, distinguishing pre-specified from } \\
\text { exploratory }\end{array}$ & $\begin{array}{l}11 \\
12-\text { Table } 3\end{array}$ \\
\hline Harms & 19 & $\begin{array}{l}\text { All important harms or unintended effects in } \\
\text { each group (for specific guidance see } \\
\text { CONSORT for harms) }\end{array}$ & Not applicable \\
\hline \multicolumn{4}{|l|}{ Discussion } \\
\hline Limitations & 20 & $\begin{array}{l}\text { Trial limitations, addressing sources of } \\
\text { potential bias, imprecision, and, if relevant, } \\
\text { multiplicity of analyses }\end{array}$ & 14 \\
\hline Generalisability & 21 & $\begin{array}{l}\text { Generalisability (external validity, } \\
\text { applicability) of the trial findings }\end{array}$ & 13 \\
\hline Interpretation & 22 & $\begin{array}{l}\text { Interpretation consistent with results, } \\
\text { balancing benefits and harms, and } \\
\text { considering other relevant evidence }\end{array}$ & $13-14$ \\
\hline \multicolumn{4}{|l|}{ Other information } \\
\hline Registration & 23 & $\begin{array}{l}\text { Registration number and name of trial } \\
\text { registry }\end{array}$ & 3 \\
\hline Protocol & 24 & $\begin{array}{l}\text { Where the full trial protocol can be accessed, } \\
\text { if available }\end{array}$ & Not applicable \\
\hline Funding & 25 & $\begin{array}{l}\text { Sources of funding and other support (such } \\
\text { as supply of drugs), role of funders }\end{array}$ & 14 \\
\hline
\end{tabular}

\section{Appendix B}

\section{T棓ieR}

Template for Intervention Description and Replication
The TIDieR (Template for Intervention Description and Replication) Checklist *:

Information to include when describing an intervention and the location of the information

\begin{tabular}{lll}
\hline \multirow{2}{*}{ Item Number } & \multicolumn{1}{c}{ Item } & $\begin{array}{c}\text { Primary Paper } \\
\text { (Page or Appendix } \\
\text { Number) }\end{array}$ \\
\hline & BRIEF NAME & Other $^{\dagger}$ (Details) \\
\hline 1. & $\begin{array}{l}\text { Provide the name or a phrase that describes the } \\
\text { intervention. }\end{array}$ & n/a \\
\hline & WHY & \\
\hline 2. & $\begin{array}{l}\text { Describe any rationale, theory, or goal of the elements } \\
\text { essential to the intervention. }\end{array}$ & $2-5$ \\
\hline
\end{tabular}




\begin{tabular}{|c|c|c|c|}
\hline \multirow{2}{*}{ Item Number } & \multirow[t]{2}{*}{ Item } & \multicolumn{2}{|c|}{ Where Located ** } \\
\hline & & $\begin{array}{l}\text { Primary Paper } \\
\text { (Page or Appendix } \\
\text { Number) }\end{array}$ & Other $^{+}$(Details) \\
\hline & WHAT & & \\
\hline 3. & $\begin{array}{l}\text { Materials: Describe any physical or informational } \\
\text { materials used in the intervention, including those } \\
\text { provided to participants or used in intervention } \\
\text { delivery or in training of intervention providers. } \\
\text { Provide information on where the materials can be } \\
\text { accessed (e.g., online appendix, URL). }\end{array}$ & $4-5$ & \\
\hline \multirow[t]{2}{*}{4.} & $\begin{array}{l}\text { Procedures: Describe each of the procedures, } \\
\text { activities, and/or processes used in the intervention, } \\
\text { including any enabling or support activities. }\end{array}$ & 5 & - \\
\hline & WHO PROVIDED & & \\
\hline \multirow[t]{2}{*}{5.} & $\begin{array}{l}\text { For each category of intervention provider (e.g., } \\
\text { psychologist, nursing assistant), describe their } \\
\text { expertise, background and any specific } \\
\text { training given. }\end{array}$ & $5-6$ & \\
\hline & HOW & & \\
\hline \multirow[t]{2}{*}{6.} & $\begin{array}{l}\text { Describe the modes of delivery (e.g., face-to-face or } \\
\text { by some other mechanism, such as internet or } \\
\text { telephone) of the intervention and whether it was } \\
\text { provided individually or in a group. }\end{array}$ & $5-6$ & \\
\hline & WHERE & & \\
\hline \multirow[t]{2}{*}{7.} & $\begin{array}{l}\text { Describe the type(s) of location(s) where the } \\
\text { intervention occurred, including any necessary } \\
\text { infrastructure or relevant features. }\end{array}$ & $5-6$ & \\
\hline & WHEN and HOW MUCH & & \\
\hline \multirow[t]{2}{*}{8.} & $\begin{array}{l}\text { Describe the number of times the intervention was } \\
\text { delivered and over what period of time including the } \\
\text { number of sessions, their schedule, and their } \\
\text { duration, intensity or dose. }\end{array}$ & $5-6$ & \\
\hline & TAILORING & & \\
\hline \multirow[t]{2}{*}{9.} & $\begin{array}{l}\text { If the intervention was planned to be personalised, } \\
\text { titrated or adapted, then describe what, why, when, } \\
\text { and how. }\end{array}$ & 4 & \\
\hline & MODIFICATIONS & & \\
\hline \multirow[t]{2}{*}{$10 .^{+}$} & $\begin{array}{l}\text { If the intervention was modified during the course of } \\
\text { the study, describe the changes (what, why, when, } \\
\text { and how). }\end{array}$ & Not applicable & $\begin{array}{l}\text { Recruitment location } \\
\text { modified as per } 2.2\end{array}$ \\
\hline & HOW WELL & & \\
\hline 11. & $\begin{array}{l}\text { Planned: If intervention adherence or fidelity was } \\
\text { assessed, describe how and by whom, and if any } \\
\text { strategies were used to maintain or improve fidelity, } \\
\text { describe them. }\end{array}$ & 5-not assessed & \\
\hline $12 .^{+}$ & $\begin{array}{l}\text { Actual: If intervention adherence or fidelity was } \\
\text { assessed, describe the extent to which the } \\
\text { intervention was delivered as planned. }\end{array}$ & Not assessed & \\
\hline
\end{tabular}

** Authors-use N/A if an item is not applicable for the intervention being described. Reviewers-use '?' if information about the element is not reported/not sufficiently reported. + If the information is not provided in the primary paper, give details of where this information is available. This may include locations such as a published protocol or other published papers (provide citation details) or a website (provide the URL). ${ }^{\ddagger}$ If completing the TIDieR checklist for a protocol, these items are not relevant to the protocol and cannot be described until the study is complete. * We strongly recommend using this checklist in conjunction with the TIDieR guide (see BMJ 2014; 348:g1687) which contains an explanation and elaboration for each item. * The focus of TIDieR is on reporting details of the intervention elements (and where relevant, comparison elements) of a study. Other elements and methodological features of studies are covered by other reporting statements and checklists and have not been duplicated as part of the TIDieR checklist. When a randomised trial is being reported, the TIDieR checklist should be used in conjunction with the CONSORT statement (see www.consort-statement.org) as an extension of Item 5 of the CONSORT 2010 Statement. When a clinical trial protocol is being reported, the TIDieR checklist should be used in conjunction with the SPIRIT statement as an extension of Item 11 of the SPIRIT 2013 Statement (see www.spirit-statement.org). For alternate study designs, TIDieR can be used in conjunction with the appropriate checklist for that study design (see www.equator-network.org). 


\section{Appendix C}

Table A1. Sample description by country for study 1 .

\begin{tabular}{|c|c|c|c|c|c|c|c|c|c|c|c|c|c|c|c|c|}
\hline & $\begin{array}{l}\text { Ireland, All } \\
\text { Groups }\end{array}$ & $\begin{array}{c}\text { Group } \\
1\end{array}$ & $\begin{array}{c}\text { Group } \\
2\end{array}$ & $\begin{array}{c}\text { Group } \\
3\end{array}$ & $\begin{array}{l}\text { UK, All } \\
\text { Groups }\end{array}$ & $\begin{array}{c}\text { Group } \\
1\end{array}$ & $\begin{array}{c}\text { Group } \\
2\end{array}$ & $\begin{array}{c}\text { Group } \\
3\end{array}$ & $\begin{array}{l}\text { Malaysia, } \\
\text { All Groups }\end{array}$ & $\begin{array}{c}\text { Group } \\
1\end{array}$ & $\begin{array}{c}\text { Group } \\
2\end{array}$ & $\begin{array}{c}\text { Group } \\
3\end{array}$ & $\begin{array}{l}\text { India, All } \\
\text { Groups }\end{array}$ & $\begin{array}{c}\text { Group } \\
1\end{array}$ & $\begin{array}{c}\text { Group } \\
2\end{array}$ & $\begin{array}{c}\text { Group } \\
3\end{array}$ \\
\hline $\begin{array}{l}\text { Age (mean, } \\
\text { SD) }\end{array}$ & $37.1(17.7)$ & $\begin{array}{c}36.9 \\
(17.4) \\
\end{array}$ & $\begin{array}{l}36.7 \\
(17.4)\end{array}$ & $\begin{array}{l}37.6 \\
(18.5) \\
\end{array}$ & $46.1(18.8)$ & $\begin{array}{c}45.3 \\
(19.0) \\
\end{array}$ & $\begin{array}{c}46.8 \\
(19.3) \\
\end{array}$ & $\begin{array}{c}46.1 \\
(18.3) \\
\end{array}$ & $19.7(4.17)$ & $\begin{array}{c}19.5 \\
(4.19)\end{array}$ & $\begin{array}{c}20.0 \\
(4.25)\end{array}$ & $\begin{array}{l}19.6 \\
(4.14)\end{array}$ & $22.6(6.67)$ & $\begin{array}{c}24.2 \\
(8.72)\end{array}$ & $\begin{array}{l}22.8 \\
(5.50)\end{array}$ & $\begin{array}{l}21.4 \\
(5.18)\end{array}$ \\
\hline Women & $45.8 \%$ & $44.4 \%$ & $44.2 \%$ & $49.3 \%$ & $46.1 \%$ & $39.1 \%$ & $45.7 \%$ & $54.7 \%$ & $65.7 \%$ & $56.3 \%$ & $69.4 \%$ & $71.4 \%$ & $76.2 \%$ & $81.8 \%$ & $84.1 \%$ & $67.1 \%$ \\
\hline $\begin{array}{c}\text { Private health } \\
\text { insurance }{ }^{+}\end{array}$ & $67.1 \%$ & $63.4 \%$ & $59.7 \%$ & $83 \%$ & + & $t$ & $t$ & + & $39.3 \%$ & $38.3 \%$ & $42.6 \%$ & $37.0 \%$ & $24.1 \%$ & $30.9 \%$ & $13.3 \%$ & $25.7 \%$ \\
\hline \multicolumn{17}{|l|}{$\begin{array}{l}\text { Do you know } \\
\text { someone who } \\
\text { (\% yes) }\end{array}$} \\
\hline $\begin{array}{l}\text { has received } \\
\text { an organ }\end{array}$ & $21.0 \%$ & $20 \%$ & $20 \%$ & $31 \%$ & $13.0 \%$ & $11.5 \%$ & $12.4 \%$ & $15.1 \%$ & $15.8 \%$ & $8.33 \%$ & $20.4 \%$ & $18.4 \%$ & $20.7 \%$ & $26 \%$ & $26.8 \%$ & $13.7 \%$ \\
\hline $\begin{array}{c}\text { needs an } \\
\text { organ }\end{array}$ & $16.1 \%$ & $15.2 \%$ & $14.6 \%$ & $18.8 \%$ & $5.1 \%$ & $2.3 \%$ & $9.88 \%$ & $3.49 \%$ & $16.4 \%$ & $14.6 \%$ & $18.4 \%$ & $16.3 \%$ & $7.69 \%$ & $3.7 \%$ & $11.9 \%$ & $8.22 \%$ \\
\hline $\begin{array}{l}\text { has donated } \\
\text { an organ }\end{array}$ & $12.8 \%$ & $12.6 \%$ & $15.2 \%$ & $10.5 \%$ & $8.27 \%$ & $4.6 \%$ & $9.88 \%$ & $10.5 \%$ & $11.0 \%$ & $8.33 \%$ & $14.3 \%$ & $10.2 \%$ & $23.0 \%$ & $26.0 \%$ & $26.2 \%$ & $19.2 \%$ \\
\hline $\begin{array}{l}\text { Ever donated } \\
\text { blood }\end{array}$ & $37.2 \%$ & $34.4 \%$ & $38.2 \%$ & $39.1 \%$ & $46.9 \%$ & $46.0 \%$ & $48.2 \%$ & $46.5 \%$ & $24.7 \%$ & $27.1 \%$ & $34.7 \%$ & $12.2 \%$ & $18.2 \%$ & $14.6 \%$ & $16.7 \%$ & $21.9 \%$ \\
\hline
\end{tabular}




\section{References}

1. Doherty, S.; Dolan, E.; Flynn, J.; O'Carroll, R.E.; Doyle, F. Circumventing the 'ick' factor: A randomised trial of the effects of omitting affective attitudes questions to increase intention to become an organ donor. Front. Psychol. 2017, 8, 1443. [CrossRef] [PubMed]

2. Morgan, S.E.; Stephenson, M.T.; Harrison, T.R.; Afifi, W.A.; Long, S.D. Facts versus 'Feelings': How rational is the decision to become an organ donor? J. Health Psychol. 2008, 13, 644-658. [CrossRef]

3. O'Carroll, R.E.; Foster, C.; McGeechan, G.; Sandford, K.; Ferguson, E. The "ick" factor, anticipated regret, and willingness to become an organ donor. Health Psychol. 2011, 30, 236-245. [CrossRef]

4. O'Carroll, R.E.; Ferguson, E.; Hayes, P.C.; Shepherd, L. Increasing organ donation via anticipated regret (INORDAR): Protocol for a randomised controlled trial. BMC Public Health 2012, 12, 169. [CrossRef] [PubMed]

5. O'Carroll, R.E.; Shepherd, L.; Hayes, P.C.; Ferguson, E. Anticipated regret and organ donor registration: A randomized controlled trial. Health Psychol. 2016, 35, 1169-1177. [CrossRef] [PubMed]

6. Kahneman, D. Thinking, Fast and Slow; Penguin: London, UK, 2011.

7. Sprott, D.E.; Spangenberg, E.R.; Knuff, D.C.; Devezer, B. Self-prediction and patient health: Influencing health-related behaviors through self-prophecy. Med. Sci. Monit. 2006, 12, RA85-RA91. [PubMed]

8. Wilding, S.; Conner, M.; Sandberg, T.; Prestwich, A.; Lawton, R.; Wood, C.; Miles, E.; Godin, G.; Sheeran, P. The question-behaviour effect: A theoretical and methodological review and meta-analysis. Eur. Rev. Soc. Psychol. 2016, 27, 196-230. [CrossRef]

9. Rodrigues, A.M.; O’Brien, N.; French, D.P.; Glidewell, L.; Sniehotta, F.F. The question-behavior effect: Genuine effect or spurious phenomenon? A systematic review of randomized controlled trials with meta-analyses. Health Psychol. 2015, 34, 61-78. [CrossRef]

10. Nichols, A.L.; Maner, J.K. The good-subject effect: Investigating participant demand characteristics. J. Gen. Psychol. 2008, 135, 151-165. [CrossRef]

11. Perinelli, E.; Gremigni, P. Use of Social Desirability Scales in Clinical Psychology: A Systematic Review. J. Clin. Psychol. 2016, 72, 534-551. [CrossRef]

12. Bou Malham, P.; Saucier, G. The conceptual link between social desirability and cultural normativity. Int. J. Psychol. 2016, 51, 474-480. [CrossRef]

13. Dombrowski, S.U.; O'Carroll, R.E.; Williams, B. Form of delivery as a key 'active ingredient' in behaviour change interventions. Br. J. Health Psychol. 2016, 21, 733-740. [CrossRef] [PubMed]

14. Wing, R.R.; Tate, D.F.; Gorin, A.A.; Raynor, H.A.; Fava, J.L. A self-regulation program for maintenance of weight loss. N. Engl. J. Med. 2006, 355, 1563-1571. [CrossRef]

15. Murphy, R.; Hutton, P. Practitioner Review: Therapist variability, patient-reported therapeutic alliance, and clinical outcomes in adolescents undergoing mental health treatment-A systematic review and meta-analysis. J. Child Psychol. Psychiatry 2018, 59, 5-19. [CrossRef] [PubMed]

16. Del Re, A.C.; Fluckiger, C.; Horvath, A.O.; Symonds, D.; Wampold, B.E. Therapist effects in the therapeutic alliance-outcome relationship: A restricted-maximum likelihood meta-analysis. Clin. Psychol. Rev. 2012, 32, 642-649. [CrossRef]

17. Kemmelmeier, M. Cultural differences in survey responding: Issues and insights in the study of response biases. Int. J. Psychol. 2016, 51, 439-444. [CrossRef]

18. Smith, P.B.; Vignoles, V.L.; Becker, M.; Owe, E.; Easterbrook, M.J.; Brown, R.; Bourguignon, D.; Garðarsdóttir, R.B.; Kreuzbauer, R.; Ayala, B.C.; et al. Individual and culture-level components of survey response styles: A multi-level analysis using cultural models of selfhood. Int. J. Psychol. 2016, 51, 453-463. [CrossRef]

19. Boutron, I.; Moher, D.; Altman, D.G.; Schulz, K.F.; Ravaud, P.; Group, C. Methods and processes of the CONSORT Group: Example of an extension for trials assessing nonpharmacologic treatments. Ann. Intern. Med. 2008, 148, W60-W66. [CrossRef] [PubMed]

20. Hoffmann, T.C.; Glasziou, P.P.; Boutron, I.; Milne, R.; Perera, R.; Moher, D.; Altman, D.G.; Barbour, V.; Macdonald, H.; Johnston, M.; et al. Better reporting of interventions: Template for intervention description and replication (TIDieR) checklist and guide. BMJ 2014, 348, g1687. [CrossRef] [PubMed] 
21. O'Carroll, R.E.; Haddow, L.; Foley, L.; Quigley, J. If you needed an organ transplant would you have one? The effect of reciprocity priming and mode of delivery on organ donor registration intentions and behaviour. Br. J. Health Psychol. 2017, 22, 577-588. [CrossRef]

22. De Boer, M.R.; Waterlander, W.E.; Kuijper, L.D.; Steenhuis, I.H.; Twisk, J.W. Testing for baseline differences in randomized controlled trials: An unhealthy research behavior that is hard to eradicate. Int. J. Behav. Nutr. Phys. Act. 2015, 12, 4. [CrossRef]

23. Landry, C.E.; Lange, A.; List, J.A.; Price, M.K.; Rupp, N.G. Toward an understanding of the economics of charity: Evidence from a field experiment. Q. J. Econ. 2006, 121, 747-782. [CrossRef]

24. Brose, L.S.; McEwen, A.; West, R. Does it matter who you see to help you stop smoking? Short-term quit rates across specialist stop smoking practitioners in England. Addiction 2012, 107, 2029-2036. [CrossRef]

25. Gainforth, H.L.; Aujla, S.Y.; Beard, E.; Croghan, E.; West, R. Associations between Practitioner Personality and Client Quit Rates in Smoking Cessation Behavioural Support Interventions. J. Smok. Cessat. 2017, 13, 103-109. [CrossRef]

26. Falomir-Pichastor, J.M.; Berent, J.A.; Pereira, A. Social psychological factors of post-mortem organ donation: A theoretical review of determinants and promotion strategies. Health Psychol. Rev. 2013, 7, $202-247$. [CrossRef]

27. Shrout, P.E.; Stadler, G.; Lane, S.P.; McClure, M.J.; Jackson, G.L.; Clavél, F.D.; Iida, M.; Gleason, M.E.J.; Xu, J.H.; Bolger, N. Initial elevation bias in subjective reports. Proc. Natl. Acad. Sci. USA 2018, 115, E15-E23. [CrossRef]

28. Ellis, E.M.; Elwyn, G.; Nelson, W.L.; Scalia, P.; Kobrin, S.C.; Ferrer, R.A. Interventions to Engage Affective Forecasting in Health-Related Decision Making: A Meta-Analysis. Ann. Behav. Med. 2018, 52, 157-174. [CrossRef]

(C) 2019 by the authors. Licensee MDPI, Basel, Switzerland. This article is an open access article distributed under the terms and conditions of the Creative Commons Attribution (CC BY) license (http://creativecommons.org/licenses/by/4.0/). 